\title{
The spatial logic of linguistic practice: Bourdieusian inroads into language and internationalization in academe
}

\author{
L I N U S S A L Ö \\ Stockholm University and KTH Royal Institute of Technology, Sweden
}

\section{A B S T R A C T}

This article utilizes Bourdieu's sociology to grasp the relations between linguistic practice and spatiality, and, through that effort, to position language as a pivotal terrain in internationalizing academe. Empirically, it explores Swedish academe and the linguistic practices of its dwellers: Swedish-speaking and non-Swedish-speaking researchers in four disciplines. Here, Swedish co-exists with English as a lingua franca and other languages. Observational and interview data show that this situation gives rise to complex linguistic practices in the workplace, consisting of speakers alternating between Swedish and English or evading other languages. Following Bourdieu, these phenomena manifest in moments when matters of space are rendered salient. They show that linguistic practice is bound up with space to the extent that their interrelationship becomes discernable only when the spatial logic that confines linguistic practices is rejigged. While linguistic practices seemingly operate on a location-based principle, they actually pertain to speakers' linguistic habitus in relation to the linguistic market conditions in play. (Linguistic practice, space, internationalizing academe)*

Internationalization struggles: Language about and in academic life

The nineteenth-century chemist Louis Pasteur once said that Le savant a une patrie, la science n'en a pas 'the scientist has a homeland, science does not' (quote from Merton 1942/1973:272). In hindsight, this precept may be seen as a position-taking in the struggles weighing over the world of academe, which has long been caught in a tug-of-war between nationalizing and denationalizing forces, each laden with interest and power (Crawford, Shinn, \& Sörlin 1993). Such struggles remain unsettled to this day, and the ramifications they hold thus linger in contemporary struggles of university politics. In fact, Pasteur's dictum is occasionally utilized as a trope in meta-science debates on global solutions and challenges, internationalization of research and innovation, and the like. ${ }^{1}$

C The Author(s), 2020. Published by Cambridge University Press. This is an Open Access article, distributed under the terms of the Creative Commons Attribution-NonCommercial-NoDerivatives licence (http://creativecommons.org/licenses/by-nc-nd/4.0/), which permits non-commercial re-use, distribution, and reproduction in any medium, provided the original work is unaltered and is properly cited. The written permission of Cambridge University Press must be obtained for commercial re-use or in order to create a derivative work. 0047-4045/20 \$15.00 
In academe globally, internationalization is, at the same time, a strategic signal word and an essential feature of reality, affecting all of those active within it (e.g. Dubois, Gingras, \& Rosental 2016). Often, internationalization struggles outweigh language and the question of linguistic legitimacy in the academic world. Language in this realm of society is the primary object of the present article, which, using Pierre Bourdieu's sociological framework, focuses on Swedish academe. Fittingly enough, for Bourdieu academic language use was an early knowledge-interest (Bourdieu, Passeron, \& De Saint Martin 1965/1994) that would have a formative influence on his intellectual agenda. The task of exploring this object is here resumed, albeit readjusted and rescoped to center on the contemporary academic dweller, and the type of oscillating linguistic practices ushered in by today's globalizing conditions.

Indeed, for analysts of language in society, academe — our own world—lends itself to an interesting inquiry. There is, on the one hand, ample language ABout the internationalization of academic life, which typically seeks to represent the state of affairs in ways that make certain policy measures seem urgent. In Swedish policy struggles, the question of language legitimacy hinges upon representations of whether universities are national or international 'at heart'. In science policy (SP), internationalization is a much-desired ambition, believed to increase research quality and strengthen Sweden's position in global competition. Here, internationalization is also believed to align with a return to a set of authentic values held by the academic world, such as Mertonian norms of scientific universalism and internationalism. Recently, for example, the governmental Inquiry of Internationalization prefaced its first report by asserting that 'The activities of higher education are international by nature' (Ministry of Education and Research 2018:31) and, from this vantage point, encouraged greater use of English in Swedish academe. This position clashes with the stance standardly proposed in the adjacent field of language planning and policy (LPP). There, it is accentuated that Swedish universities are nationally embedded and societally relevant, a fact that speaks in favor of restraining the dominance of English by a parallel exchange of knowledge through Swedish. Correspondingly, governmental LPP reports (e.g. Ministry of Culture 2008) often depict university life as a domain of society where Swedish must not be sidestepped.

On the other hand, there is language IN academic life, which oftentimes owes its characteristics to internationalization. Here, scholars of language in society can make an important contribution by positioning language as the central terrain on which 'internationalization struggles' play out, and one of the most salient arenas for the manifestation of internationalization in academe. By examining academic language use OUTSIDE the Anglophone world, a better understanding can be gained about the imbrications of linguistic market conditions that are characteristic of internationalizing academe. Such an understanding may help us grasp the extent to which science is detached from national surroundings in the sense purportedly envisioned by Pasteur and subsequently proclaimed in SP discourse, or whether more volatile orders are at play. 
As a case in point, academics working at Swedish universities predominantly use English for a range of academic practices, such as publishing, teaching, and reading. This situation is amplified by an agenda of internationalizing academic life through increased human mobility: universities recruit staff from all over the world, a fact that further augments English use in the workplace. Nonetheless, all of this happens in an internationalizing yet nationally conditioned space - a nationstate - where Swedish has long prevailed and still holds an important position. Subsequently, like elsewhere beyond the English-speaking world, Swedish-speaking scholars navigate between the lingua franca, English, and the national language, Swedish. In the workplace, this situation habitually results in alterations in linguistic practice, in ways that owe their characteristics to spatiality. Consider the following observation in (1).

\section{(1) (fieldnotes, computer science)}

Six computer scientists are sitting in a meeting room, outlining a forthcoming project. They use English, a language that all participants master, and the language used in the project draft, which is gradually taking shape. The primary rationale for using English rather than Swedish at the meeting is that one participant neither speaks nor understands Swedish sufficiently well. But, eventually the non-Swedish speaker leaves the meeting room for a few minutes. Without any sort of commentary, the remaining five scientists immediately drift into Swedish while continuing to discuss the same topic. They use Swedish until the non-Swedish-speaking scientist returns, after which they drift (almost crossfade) back into English.

How does one account for the logic of this linguistic practice, occurring as it does in a single physical space? How does one account for the fact that the linguistic practice observed seems bound to the bodily movement - the absences and presencesof users of particular languages? What kinds of knowledge do such practices entail on the part of the participating researchers, allowing them to seamlessly rejig their understanding of what it means to produce language appropriate to the situation? Beyond sharing a language-as-system, it is clear that the colleagues share 'routine ways of acting, similar perspectives, a sense of space, or common ways of evaluating speech' (Hanks 1996:13). If so, what are the constituents of this 'sense of space' and how is such a sense to be accounted for theoretically? How are these situations experienced by non-Swedish speakers, and how can their relation to linguistic practice vis-à-vis space be accounted for?

This article ponders such questions. It is essentially concerned with language choice: the organization of linguistic assets in multilingual spaces. In particular I am concerned with the effects that space, in all its intricacy, brings to bear on linguistic practices, and the linguistic strategies such practices entail. The objective is to account for the ways in which linguistic practices owe their characteristics to spatial conditions in Swedish academe, and the practical sense that socialized language users have of themselves and the value-infused environments they inhabit. 
To this end, I seek to advance an understanding of linguistic practices in internationalizing academe as occurring between people's social and physical environments, so as to better grasp the spatial logic sustained through language in this realm of society. Whereas previous related work (e.g. Salö 2015) privileges the viewpoint of Swedish speakers, the present article encompasses additionally the viewpoint of non-Swedish speakers, whose perspectives are of pivotal value for the understanding of internationalizing academe. Being 'a Swedish speaker' in this sense is neither a national or ethnic category, nor does it necessarily pertain to a notion of native speakerhood. Rather, 'Swedish speakers' denote language users whose knowledge of Swedish is deemed sufficient by others for Swedish to be socially enabled, and so include first-language as well as second-language speakers of Swedish. Accordingly, a 'non-Swedish speaker' is a speaker whose knowledge of Swedish is deemed limited to the extent that use of Swedish in the workplace is ruled out.

To account for these dynamics, I draw on Bourdieu's sociological theory of linguistic practice, which is fairly well-known among sociolinguists (e.g. Hanks 2005; Blommaert 2015; Salö 2018), combined with his arguably lesser known theory of spatiality. The upshot of this two-fold theoretical endeavor is that matters of language and space can be viewed through a comprehensive lens apt for exploring what Bourdieu (1977:89) calls 'the relationship between the body and a space', or what Ingold terms 'the RELATIONS between the dweller and the constituents of the dwelt-in world' (2000:409).

Along these lines, I hope to advance the discussion concerning the position held by English in internationalizing academe by contributing to a refined understanding of the relations between academic knowledge production, language, and location. Moreover, I seek to present, and make the case for, Bourdieu as a spatial thinker relevant to scholarship on language in society. By outlining and showcasing Bourdieu's sociological perspectives and thinking-tools, I aim to contribute to recent theoretical discussions on the ways that space organizes language regimes, how spaces are sensed and engendered in practice, and how speakers shuttle between spaces, aligning their language practices to the values imbued therein (e.g. Blommaert, Collins, \& Slembrouck 2005; Canagarajah 2013; Pennycook \& Otsuji 2015). In so doing, I also seek to probe deeper into the 'linguistic sense of placement' (Bourdieu 1991) of academic dwellers. Utilizing this notion, I endeavor to make the case for linguistic choice as spatially ordered in ways that are ostensibly location-based but are better explained in terms of linguistic habitus - speakers' dispositions to linguistic practices - as it encounters values imbued in linguistic markets. As I show, drawing on Bourdieu's insights as reinvigorated through the work of the philosopher Nikolaus Fogle (2011) and anthropologist Tim Ingold (2000), people's dispositions to linguistic practices are spatial in that they are developed vis-à-vis the dwelling agent's social as well as physical environments. This perspective is useful because it avoids the pitfall of essentializing physical space and its relationship to language, while still bearing in mind that space matters to linguistic practice. 
Accounting for the spatial logic of linguistic practice entails a research focus on the relationship between the linguistic habitus of language users and the linguistic market conditions where such users dwell (see THEORETICAL FRAMEWORK below). Pursuing such a study, the present article adopts a qualitative, critical sociolinguistics modus operandi centered on language use among a selection of differentially positioned researchers, including their reasonings for such use, in relation to sociolinguistic values at play in Swedish academe. Following Heller (2011), such an approach is realized by linking multiple research techniques, while remaining sensitive to the fact that the techniques utilized provide different points of entry and generate different kinds of data. Correspondingly, I here combine two strands of methodological procedures. One is the first-hand study of what people do with language, obtained through observations in the settings where their linguistic practices unfold. The other is to ask producers of linguistic practices to reflect on these practices, so as to yield interview accounts of the practical experiences of agents. Whereas the first procedure captures linguistic practices, the latter captures meta-linguistic practices valuable for understanding how linguistic market conditions are sensed and experienced. The latter procedure, however, requires analytical sensitivity. In particular, as we shall see, in calling upon speakers to account for their own engagement in linguistic practice, they often produce accounts that seem reasonable, where rationalizations typically mirror conditions that they tacitly accept (Hanks 2005). Hence, the interviewees' common-sense accounts of their practices need also be accounted for theoretically. Here, Bourdieu's lens stands in good stead as it reveals 'the interests that are served by the banality of practice' (Cresswell 2002:381).

Correspondingly, the dataset consists of observations of linguistic practice as well as interview accounts produced by researchers active in four disciplinary fields of Swedish academe: psychology, computer science, mathematics, and history. The subjects are Swedish speakers (computer science and psychology) and non-Swedish speakers (mathematics and history) in the practice-implicational sense outlined above and further discussed throughout the article. The empirical material was first compiled in relation to a larger research project on language issues and phenomena in Swedish academe from 2011-2016, which produced a rich dataset of meeting recordings, fieldnotes, and interviews (see Salö 2016 for details). For the present article, observable yet under-explored observation and interview accounts from computer science and psychology were extracted from the dataset. From 2017 to 2018, additional observations and hour-long interviews were conducted in mathematics and history, and were subsequently added to the dataset in the form of fieldnotes and transcriptions.

In working through this dataset, the procedure consisted of locating moments where the participants' embodied knowledge of market conditions was rendered salient. I manually selected instances of observed practices and interview accounts 
that seemed to be related to, conditioned by, or contingent upon space, insofar as they either revealed spatially infused linguistic strategies or adhered to prevalent principles relevant to language and space. In analyzing such instances qualitatively, I sought to unravel ways in which space — social and physical — appeared as a structuring feature in linguistic practice, as understood within the chosen theoretical framework (see below).

\section{THEORETICA L F R A MEWOR K}

\section{Space and language: Towards a Bourdieusian account}

Contemporary scholarship on language in society increasingly addresses spatiality in respect to different kinds of language-oriented analyses (see Higgins 2017 for an overview). For example, Markus \& Cameron (2002) provide a compelling account of language ABOUT the material spaces of buildings, and so explore the intersection of sociolinguistics and architecture. Attention to the relationship between language and physical space has also been made via the notion of linguistic/semiotic landscapes (e.g. Jaworski \& Thurlow 2010). A stronger social orientation, arguably, is found in work that sheds light on the 'spatial repertoires' (e.g. Pennycook \& Otsuji 2015) or the 'spaces of multilingualism' that crystalize in globalizing contexts (Blommaert et al. 2005).

The present article partly aligns with this broad intellectual agenda. I share with Markus \& Cameron (2002) an interest in language IN RELATION TO physical rooms and other architectural reifications of space, and with Blommaert et al. (2005) an interest in language knowledge and communicative behavior in relation to spatial environments. Crucially, however, I place at center stage the relations between social space and linguistic practice, and for this reason, I additionally encompass a theory of practice. On this note, spatially interested sociolinguistics has been prone to grounding its accounts on space in the work of certain French philosophers in the poststructural tradition, notably Michel De Certeau and Henri Lefebvre (see Higgins 2017). Here I draw instead on Bourdieu's contemporaneous account, which like Lefebvre's but unlike De Certeau's, centers intellectually on incarnated durable dispositions - habitus - as a core feature of his theory of practice. In what follows, I outline Bourdieu's account of spatiality, followed by his account of linguistic practice.

\section{Bourdieu as a spatial thinker}

Bourdieu's account of spatiality was developed in numerous publications over the course of many years. His matured account comprises two key components: social and physical space. These modes of space, as he stresses throughout, appear seemingly discrete but are, in fact, interdependent in that they assume, and create the conditions for, each other. Physical space, to begin, concerns geographic locations and environments: built spaces such as buildings and rooms with a concrete material 
existence. The privileging of this perspective was prominent in some of Bourdieu's early ethnological work, for instance, in his analyses of the Berber house in post-war Algeria (Bourdieu 1970), where particular everyday practices were shown to be spatially bound to particular physical locations in the buildings. Later, Bourdieu (1990:9) himself commented on these studies as 'Perhaps the last work I wrote as a blissful structuralist'. His thenceforth developed notion of social space is more intangible and, by virtue of its varied applications in Bourdieu's theorizing, certainly harder to grasp. In one of its usages, social space means something akin to 'society' - the overarching social world within which more or less autonomous social fields are placed. However, beyond being a tool for theoretical modelling, social space is a feature of reality 'just as real as geographical space' (Bourdieu 1991:232). In this latter usage, social space often serves as a sYMBOLIC space, denoting the arena in which people act and occupy positions, and which is phenomenologically experienced by, and so incarnated in, social agents. 'Social agents', Bourdieu stipulates accordingly, 'are constituted in, and in relationship to, a social space' (1993a:124, emphasis removed). In this sense, social space is, in effect, most palpably manifested in its historically embodied mode of existence: in people, or, more specifically, in their habitus (see below), which 'is literally incorporated by long exposure to a given region of social space' (Fogle 2011:14). The fact that 'social' here incorporates 'symbolic' is saliently manifested in language, where differences associated with social positions assume symbolic values, that is, are rendered into symbolic differences (Bourdieu 1996:17).

For Bourdieu, as noted, physical space and social space are inter-reliantmanifested in and transmitted into one another. As an illustration, a key observation in Bourdieu's (1970) work on the Berber houses was that spatially specific practices were often gendered; women, for instance, conducted particular household duties in particular locations within the house, in a sense that tied physical space to social space and the structures at work there. Physical space, Bourdieu came to argue, is 'reified social space' (Bourdieu 1993a:126). As Bourdieusian theorist Fogle (2011) persuasively argues, while physical space often serves as a pivotal template for the organization of the social world, providing its material conditions of existence, physical spaces are already social because the environment is built. This point was aptly pinpointed by Winston Churchill in noting that 'We shape our buildings and afterward our buildings shape us' (quoted in Fogle 2011:50).

Thus, human agents make physical space social and social space physical. It may be suggested that such spatializing phenomena unfold through the practices of social agents and the knowledge they come to embody in both physical and mental actions (Curtis 2015). In Ingold's (2000) account, human agents come to embody both of these modes of space through the human condition of $d w e l l i n g$; as he asserts, ' $[\mathrm{k}]$ nowledge of the world is gained by moving about in it, attending to it, ever alert to the signs by which it is revealed' (2000:55). Dwelling, perceived as a mundane mode of socialization, instills on the part of the agent 'a sense of the 
equivalences between physical space and social space' (Bourdieu 1990:71). This 'instilled sense' may be conceptualized as a form of incorporated practical knowledge stemming from a biographically acquired skill of perceiving the environment.

Sharing this position, Fogle (2011) places analytical weight on the role of habitus as the mediator between social and physical modes of space. Acquired through the agent's encounters with social AND physical environments, habitus may be defined as 'the system of deeply incorporated ways of being, doing, thinking, and perceiving, which social agents owe to the mode of socialization to which they have been subjected' (Bourdieu 2017:292). Through such adaptive exposure - equally structured and structuring-social agents come to incorporate the worlds they live in, and so acquire particular historically embodied dispositions to action. As Ingold puts it, they 'come literally to carry the forms of the dwellings in their bodies - in specific skills, sensibilities and dispositions' (Ingold 2000:186). Accordingly, social agents' involvement in social life results in a kind of knowledge that is, above all, obtained through their involvement with others.

Through such involvement, people acquire the specific dispositions and sensibilities that lead them to orient themselves in relation to their environment and to attend to its features in the particular ways that they do. These dispositions and sensibilities add up to what Bourdieu calls the habitus. (Ingold 2000:162)

\section{Habitus, markets, and spatial practices of language}

Because some of the skills, sensibilities, and dispositions endowed in habitus pertain to language, habitus provides a key inroad into a Bourdieusian spatial logic of linguistic practice. A more precise vantage point is provided here by the notion of linguistic habitus, conceptualized as a subentity of habitus whose characteristics pertain chiefly to language and to dispositions of communication more generally. One implication of this position is that language users, through prolonged experiences of occupying positions in space, embody linguistic dispositions, which predisposes them to perceive and act in certain ways. Habitus, however, is an insufficient component in Bourdieu's understanding of linguistic practice on its own. In invoking the formula 'linguistic habitus + linguistic market $=$ linguistic expression, speech', Bourdieu (1993b:78) privileges a relational conception of linguistic practice, where sociolinguistic matters beyond the speaking individual require additional analytical attention. Bourdieu's notion of linguistic market seeks to do precisely this, and it lies accordingly at the core of his understanding of linguistic practices as PARTLY constrained by outer, valorizing conditions. Essentially, this is why practices of linguistic exchange are permeated with symbolic power, where power relations between linguistic producers and their social collectives are actualized (Bourdieu 1991:37).

As linguistic habitus produces linguistic practices, the linguistic products are put on a linguistic market and are assessed, evaluated, and price-determined 
(Bourdieu 1993b:79). Linguistic markets, then, are value-imbued spaces of sociolinguistic sanctions and censorships, in relation to which linguistic products acquire their value. In their capacity of being spaces, markets have social and physical constituents and are subsequently sustained through language users' shared, endowed dispositions, as well as through the material display of language in artifacts, statebacked policies, and the like.

While Bourdieu's schematic outline is useful, it must be remembered that linguistic habitus and linguistic markets are not disconnected analytical entities but two modes of history contingent upon one another. While linguistic habitus is the embodied product of linguistic market conditions bestowed throughout the lifespan, linguistic markets are manufactured by human beings and subsequently sustained because the values they endorse are reproduced in practice by language users who act in accordance with their embodied schemes of perception. Far from macroladen, the ramifications of this logic are situation-specific. When socialized agents speak, their habitus encounters particular values inscribed in historically contingent market conditions that are actualized in those situations. For Bourdieu, the conditions of linguistic markets - engrained ideas about linguistic acceptability, appropriateness, correctness, and so on-are actualized and keenly 'felt' in real-life situations of linguistic exchange, and so shape the preconditions for linguistic production. Market conditions prompt language users to feel at ease in some situations and 'awkward' in others; using linguistic assets that are situationally inappropriate is typically linked to a sense of unease and, sometimes, emotional and even physical reactions.

The practical knowledge conferred by this sense of position takes the form of emotion (the unease of someone who is out of place, or the ease that comes from being in one's place), and it is expressed in behaviors such as avoidance or unconscious adjustments such as the correction of one's accent (in the presence of a person of higher rank) or, in situations of bilingualism, THE CHOICE OF THE LANGUAGE APPROPRIATE TO THE SITUATION. (Bourdieu 2000:184, emphasis added)

Markets operate on a logic that is enduring yet alterable in the micro-practices of real-life linguistic exchange. For instance, as we see below, ordinarily persistent linguistic market conditions upheld though the practices of a given category of social agents can be instantly rejigged by the sudden physical company of individual social agents and the embodied mode of social space they bring into play, resulting in adjustments in linguistic practice.

This perspective allows for an interesting social understanding of linguistic skills and knowledge: one centering on 'the capacity to produce expressions à propos, for a particular market' (Thompson 1991:18). At heart, for Bourdieu, language users do not obtain linguistic competence in isolation; their language mastery is, conversely, inseparable from the practical mastery of situations in which a particular language usage is socially enabled (Thompson 1984:46; Bourdieu 1991:82). Language users, he holds, become sensitized to the value of their linguistic assets as well as to the value imbued in the markets where they introduce their linguistic products. By this logic, Bourdieu (1991) holds that all social agents retain a 
linguistic sense of placement as a bodily, practical sense of 'knowing one's place' in relation to market assessments. Inculcated in habitus, this dual form of practical knowledge reflexively orients linguistic production because language users perceive the censorship of markets they inhabit and to which they, through selfcensorship, are inclined to adapt (Thompson 1984:57ff.; see Salö 2015).

\section{Language in Swedish academe}

In Sweden, the prevailing position of English in academe was first noticed in the early 1990s. Through the critical LPP discussions this perceived situation triggered, the sociolinguistic conditions in academe were framed much as if university life as a whole was an English-only domain, as purportedly evident in teaching practices and by publishing in the hard sciences (see Salö 2016). However, as the debate progressed, more nuanced reasonings were also put forward. Melander (2001), for instance, pointed to the difference for Swedish speakers between using English for publication and using English with Swedish friends and acquaintances. As he noted, 'A Swede who starts to use English outside the accepted domains would no doubt face strong social sanctions. He or she would be regarded as odd at best; by most probably as affected, ridiculous and in general, socially incompetent' (2001:26). Indeed, this point resonated with earlier empirical findings on English use in Sweden-based multinational companies (Hollqvist 1984:140), which had concluded that 'English is spoken... only when an interlocutor or listener does not speak Swedish'.

While exceptions are likely to exist, this principle seemingly holds true for a range of discursive exchanges - social, educational, professional, and otherwisein Swedish academe. Söderlundh (e.g. 2012) has shown that Swedish occurred frequently among Swedish-speaking university teachers and students even in courses that were nominally taught in English. Similarly, Salö (2015) and Salö \& Hanell (2014) demonstrated that in physics and computer science, Swedishspeaking researchers used technical and discipline-specific Swedish in their research practices, despite the fact that the scientific text-artifacts produced in these fields are virtually always produced in English. In what follows, I delve into the logic underpinning such linguistic practices.

\section{The relations between social space and linguistic practice}

A central regularity revealed in the studies reviewed above (esp. Salö 2015) is that Swedish-speaking researchers view English as the appropriate language for situations involving colleagues who have not mastered Swedish sufficiently. However, they use Swedish when it is socially enabled, for instance, in exchanges with Swedish-speaking colleagues. They typically rationalize such linguistic practices by referring to Swedish as the 'common language' and, therefore, as 'the natural' choice for communication. Likewise, the thought of using English 'unwarrantedly' - that is, in situations where all participants have mastered Swedish—is 
described as potentially 'very strange' or 'ridiculous' (Salö 2015; cf. Melander 2001). In reality, it is reported happening seldom or never, since among its speakers Swedish is the legitimate language in the micro-markets for linguistic exchanges in the workplace.

However, due to recruitment and cooperation patterns in internationalizing academe, non-Swedish speakers frequently partake in the research practice. In some situations, these dynamics lead to alternations in linguistic practice, ushered in by the presence and sudden absence of non-Swedish speakers (cf. extract (1)). This sort of practice is commented upon by a Swedish-speaking computer scientist in (2).

(2) (interview, computer scientist) ${ }^{2}$

But it is easy to note that the threshold is low for switching into English. When I was at [a Swedish university], it would typically be enough to have one person in the room who does not speak Swedish as a mother tongue, or very well, for the natural language to be English. In those contexts, you can even observe how rapidly things can change, how you develop small, local microhabitats in some way. When someone goes to the bathroom, you might actually switch into Swedish..., continue speaking about the same thing for a few minutes, and then switch back into English again when the person who is the causal factor returns from the bathroom.

The point I wish to stress is that the dynamics actualized in extract (2), one of bodies and rooms, concerns preliminarily the impact of embodied social space on linguistic practice. More profoundly, however, it demonstrates how linguistic practice is conditionally bound to space to the extent that their interrelationship is rendered salient only when spatially infused market conditions are rejigged. This latter insight is vital, because it serves to avoid a priori reasonings of space as an arrangement existing prior to linguistic practice. Rather, it stresses how linguistic practices are shaped in relation to space, where space serves as a template for the organization of linguistic assets. As noted, a firm Bourdieusian position dictates that socialized language users are endowed with a guiding sense and bodily skill of producing language tacitly aligned to the power of acceptability imbued in specific situations (Thompson 1984:7). In extract (2) we find a situation where the employment of linguistic assets is based on a notion of sociolinguistic acceptability that is nourished by the spatial presence of language users, paired with a sense of their linguistic competence, or, rather, a sense of others' linguistic habitus. In the company of non-Swedish speakers, English, rather than Swedish, is the socially enabled language, which is to say that non-Swedish-speaking language users alter the market conditions and the perceived authority of Swedish in the market conditions of the meeting room. For Swedish speakers, however, this situation is strongly conditioned by the physical presence of non-Swedish speakers. In fact, a window of only a few minutes in which Swedish is socially enabled is sufficient for drifting into its use. 
Hence, such oscillating practices comprise assessment and a spatiotemporal dimension. To some extent, to begin, the language knowledge of language users involves knowing about others' language knowledge. In step with Goodwin (1994), this capacity is lodged in the professional vision of academic dwellers, and their perspectival, socially organized ways of seeing and understanding linguistic practices, including the linguistic skills and awareness of other dwellers engaged therein (Koller 2018). Correspondingly, as extract (2) indicates, legitimate English use is based on the evaluation, tacit or not, of whether one or more interlocutors do not "speak Swedish as a mother tongue or very well".

Indeed, in this sense 'competence assessment—evaluation—is always at play in situated contact' (Blommaert et al. 2005:200). Consistently, my observations attest to there being a spatially infused principle that affects linguistic exchanges across Swedish academe. Among colleagues, there often exists a shared understanding about who is a speaker of this or that language, where being 'a speaker' essentially means whether a given language can be used, either productively or receptively, for particular ends. Swedish-speaking researchers keep careful track of who is participating in the linguistic exchange of social-professional life, and of the drift between Swedish and English in ways that exhibit both ample knowledge and timing. Academic dwellers are attentive to features of their environments; their choice of language is guided by a number of strategies, endowed in habitus as a practical sense of using language in ways regarded as socially acceptable by others. Often, such strategies hinge upon perceptions of the extent to which non-Swedish speakers partake in exchanges or not. This latter assessment has a clear spatial component because the extent to which attributed non-Swedish speakers actually engage in conversations is gauged on the basis of cues: how close potential interlocutors are physically positioned, whether they signal a willingness to participate, and so on.

Naturally, however, such evaluation is subject to change over time. Importantly, habitus - thus including linguistic habitus - is a product of history and time, which produces individual AS WELL AS collective practices (Bourdieu 1990:54). To illustrate, the computer scientist recalls his research group being joined by a German colleague, whose presence initially entailed English use at meetings. Yet, in due time, and through the colleague's learning trajectory of Swedish, the market conditions constraining their linguistic practices changed.

(3) (interview, computer scientist)

There was a turning point, and I don't recall exactly how long it took. But say, by way of guessing, not longer than a year later we spoke Swedish with him too. There was, so to speak, a gradual change of outcome of this negotiation.

This extract highlights a distinct temporalizing facet of practice. As Bourdieu (2000:206-207) emphasizes, practice does not merely unfold over time but 'makes time'. By the same token, it is noteworthy that the work of time (Bourdieu 
1990:98-111) impacts not only the accumulation of Swedish-language assets by the German dweller but also the perception schemes of colleagues who evaluate the rhythm of his movement and eventually recategorize him as 'a Swedish speaker'. Thus, over time, the German colleague is made into a Swedish speaker by social agents already construed as belonging to that social collective, or is awarded RECOGNITION AS belonging to a linguistically defined group, united by their mutual dispositions (cf. Blommaert 2015:11).

Notably, the computer scientist's account in (2) also points to certain relationships between language use and the physical spaces of rooms in the department. An academic workplace typically comprises physical demarcations within it, separating offices from kitchens, labs, bathrooms, and seminar rooms. These are rooms constructed with the idea that certain activities typically and preferably occur in certain physical spaces. The computer scientist positions the meeting room as a common professional space, where the lingua franca, English, subsequently holds currency as the language of inclusion, given that non-Swedish speakers are present. This point is salient also in extract (4), provided by a Swedish-speaking psychologist. Her account similarly points to salient dispositions to linguistic practice, the principle of which dictates that Swedish speakers use Swedish among themselves. She is part of a closely-knit research group, whose members all speak Swedish, with extensive experience in previous collaborations. Anchored in previous practices and entangled in social relations, Swedish is the language of their online and offline meetings, their email correspondence, and so on. However, as in extract (2), the psychologist reports that English often serves as the working language, as abundances of academic events involve participants with an insufficient grasp of Swedish.

(4) (interview, psychologist)

We currently have several German PhD students, and we have not come so far that we use German. Rather, we speak English at our meetings. We normally speak Swedish among ourselves. The same goes for [another Swedish university] where we have lots of $\mathrm{PhD}$ students and people from different places. There we use English, kind of as a corporate language, and now not long ago we were conferring that we should start using Swedish always in the fika room [lunchroom for staff], so as to aid the learning of Swedish.

The psychologist here draws attention to a number of interesting features concerning the ways in which linguistic assets relate to the spatial demarcation of rooms in the workplace. Reference is made to the fika room, a common area where staff members take their lunch and coffee breaks. Here, a notion of sociality affects linguistic practice, as a cultural feature of the Swedish notion of fika is that it carries the connotations of being enmeshed in a social event of communicative exchange (Ehn \& Löfgren 2010). In short, people typically drink coffee and converse informally. In their study on 'kitchen talk' in Danish academe, Hazel \& Mortensen 
(2013:4) similarly note that 'the kitchen represents a space where institutionally implemented regulations and norms of conduct, including norms related to language choice, are less formalized than for instance in classroom, library or office settings'. Accordingly, in the psychologist's account in (4), the fika room is framed as a space central to everyday conversation, small talk, and even integration. As she reports, there are tentative plans to increase the use of Swedish in this space, so as to scaffold non-Swedish speakers' learning of the language. This way of utilizing space, that is, as an arguably well-intentioned way of imposing Swedish, has also been observed in other studies (Negretti \& Garcia-Yeste 2015).

\section{The viewpoint of non-Swedish speakers}

The fact that linguistic practices are often managed 'in silence', without explicit rules and policies, suggests that certain dispositions to linguistic practice are shared (e.g. Ingold 2000:409). However, due to global influx, Swedish academe is a diverse site where there is little reason to assume that speakers' dispositions are the product of identical or similar socialization (see Thompson 1984). Rather, by virtue of their internationalizing pursuit, universities are sites marked by an ample degree of throwntogetherness (Massey 2005) of linguistic habitus that were not crafted in relation to the same linguistic market conditions. To explicate further, we now turn to the linguistic experiences of non-Swedish speakers who share neither majority-based linguistic assets nor dispositions to linguistic practice imbued through exposure to the market values relevant to Swedish academe. Obviously, however, they too embody the skills, sensibilities, dispositions, and other forms of dwellings that Ingold (2000:186) alludes to, all of which bear on the spatial logic of their linguistic practices.

The first account comes from a British mathematician whose skills in Swedish are, by his own assessment, limited. Recalling the account presented in extract (2), the mathematician's participation in workplace conversations constitutes a 'causal factor', in that his physical presence alters market conditions in ways that affect linguistic practice: his presence prompts Swedish-speaking colleagues to drift into English. As shown in extract (5), the influence his attendance has on linguistic practice is something he has noted and reflected upon, particularly so in the social settings of the academic workplace, also discussed in relation to extract (4).

(5) (interview, mathematician)

Linus: What characterizes the coffee room in terms of language?

Mathematician: It depends very much on who's there. In a conversation where everyone is comfortable in Swedish, it will happen in Swedish. But as soon as there's anyone who is noticeably not comfortable in Swedish, everyone will happily switch over to English. And pretty much seamlessly also, there is no kind of break in the conversation. 
Linus: Would you be the kind of person that would make people switch?

Mathematician: Ehrm, let's say if I am taking part in the conversation significantly, then yes. If I am sort of sitting, listening at a smiling and nodding kind of level,... now they don't feel the need to so much. But if I am actually participating in a conversation, I will be trying to say something in Swedish and it will be halting enough that either I or they will switch to English from frustration.

According to the mathematician in (5), Swedish is often the preferred language in the coffee room (cf. Negretti \& Garcia-Yeste 2015), although Swedish speakers will "happily" switch to English if socially warranted. Colleagues thus shuttle between Swedish and English in ways that remain sensitive to the linguistic assets of their interlocutors, and the habitus that mediates these. The mathematician reports having observed "seamless" alternations in linguistic practice among his Swedish-speaking peers. He also seems to have grasped the ways that his own bodily movement in such exchanges rejigs the market conditions that otherwise enable Swedish use in the physical space of the kitchen. This does not imply, however, that physical spaces correspond straightforwardly to the utilization of particular linguistic assets. Rather, the mathematician senses, the logic by which different languages are used operates on a participant basis.

(6) (interview, mathematician)

Certain mixes of people tend to happen in certain rooms and so then rooms end up more often being in that language. But I don't have any feeling of that association carrying over to when something else is in that room. So, for instance, the seminar room where the seminars are always in English, when there are Swedish colleagues having a conversation there, they will still be conversing in Swedish I would say.

The second example derives from a group of Italian researchers working in a history department. Observation informed me that they regularly spoke English among themselves when conversing in common spaces at work, even when only Italian speakers participated in the conversations. In light of the Swedish speakers' reported awkwardness in using English unwarrantedly, this observed practice appeared to operate according to an alternative social logic, sanctioning the use of the lingua franca, English, among themselves, while rendering Italian, their first language, inappropriate in spaces such as the kitchen. In extracts (7) and (8), two of the historians, Luigi and Rafael, discuss the logic of their linguistic practices.

(7) (interview, historians)

1 Linus: I have noticed that you speak English in the kitchen here, and I find that quite interesting. Could you reflect upon why you do that? 
Luigi: I can start. I think that even if we are both, you know, this is not our first language, I think that the big difference is more a matter of the space rather than the language per se. Since the kitchen is actually a common space, we try to speak a language that is a common language. And while we are among us, you know, generally in my office for instance, we can actually speak our language. So, this is I think the big difference. So, no matter if somebody is actually around, for me it is a welcoming practice. You know, by definition you are saying to people that they can join. If I am using my own language, I am saying by definition please don't come.

3 Linus: Right.

4 Rafael: I mean, we are lucky enough that we can work in English in Sweden, and we don't need to speak Swedish, which for us would be funny, let's say. We don't really know it. And so, I mean, the idea of keeping open the space for conversation and for other people to contribute. It just feels natural, the right thing to do.

5 Linus: Is this way of using language something that you have spoken about? Have you sort of uttered a kind of agreement that when we are in the kitchen, we use English?

6 Luigi: I think not, I think not. I think that we have never really made an agreement. I think that it is kind of natural in a sense. For me it is also a matter of being understood. Basically, if someone is overhearing us, I don't want to give the impression that it is impossible to know what we are saying.

7 Rafael: We are not sharing secrets.

8 Luigi: I mean, I think [the] Swedish, they really like this transparent and transparency word. ... I think it is a way of being transparent. And you know, I could also tell you, if there is something that is really private that I want to tell Rafael, I would probably use Italian, but I would rather prefer not to do this now, while you are here. It would be just rude. I don't need to do this now right.

9 Rafael: Really, I mean, this is not Italy, Italian is not a common language. So, I mean, you should keep it open. You should let everybody [have] the possibly to participate. And, yeah, it just feels right.

10 Luigi: For me it is a way to show that I am really trying to be part of a community without excluding anybody.

By dwelling in the social world of Swedish academe, the two Italian-speaking historians have attained a sense of the market conditions in play there, which is rendered apprehensible in spatial terms. Luigi (line 2) is quick to point out that their linguistic practices pertain to space rather than language per se. The kitchen, where staff has lunch, is considered to be a common space, where two languages are socially acceptable: Swedish or English. Other languages, including Italian, are seen as not having a rightful place in this environment - at once physical and social - ultimately because such languages cannot be used as discursive tools of inclusion and openness in the workplace. Both interviewees seem utterly uninterested in having an Italian enclave amid internationalizing language conditions. Their 
accounts seem rather harmonized and follow the logic of common space-common language/noncommon space-our language, viz. Italian. At heart, they are keen on contributing to communality: being understood, transparent, and welcoming. As Rafael (line 4) notes, "It just feels natural".

Although not speaking Swedish themselves, they justify the legitimate place of Swedish by making reference to Sweden as a national space, where Swedish has its valid place, and where Swedish universities are located. They seem unwilling to question the utilization of Swedish here, even in times of rapid internationalization and despite the fact that Swedish use excludes them. In fact, their use of English appears to be a strategy of the linguistic habitus - a way of compensating for the fact that, as of yet, they do not speak Swedish sufficiently well (line 4). In fact, like the Swedish-speaking computer scientist in extract (2), Rafael and Luigi both adhere to a notion of linguistic naturalness; yet, the logic they invoke differs substantially in its practical application. English among Italian speakers is perceived as natural. Language use is thus justified, or at least rationalized, in terms of naturalness; as Hanks (2005:78) puts it, 'the ontological complicity between linguistic and social categories makes each of them appear natural'.

The reason, again, has to do with spatiality, and their sense of their linguistic assets in relation to the market conditions where they dwell. This sense drives their linguistic practices: they avoid Italian in common spaces because doing so is deemed appropriate and they circumvent Swedish because they have not mastered it. What is left is English, a language thought to be shared by all. However, physical space comes into play insofar as Italian is reported to be used behind closed doors, such as in Luigi's office (line 2). Since his office is not perceived to be a common space, the use of an uncommon language is considered acceptable there.

Through socialization, such adjustment patterns are embodied as spatial orientations to limits. Notably, however, they are sustained not because the historians follow rules or adhere to agreements (lines 5-6) but because of a shared strategy (see Lamaison \& Bourdieu 1986), in this case, a strategy of creating a fit between their linguistic habitus and the values endorsed in the markets they inhabit. Guided by the practical sense that influences their linguistic practices, using English is, or is rationalized as, a reasonable strategy for navigating Swedish academe linguistically. As seen in the next extract, these spatially bespoken linguistic-market conditions trump feelings of unease linked to speaking English to other Italian speakers.

(8) (interview, historians)

11 Linus: When I have studied these things and spoken to Swedish people, they say that obviously they switch to English when other people are participating but, for them, speaking English among themselves is... there is something 
very awkward and unnatural, they say, about that. So, it takes more, it seems, for them to switch to English. Not just the sort of potential event of someone overhearing you but rather someone's active attempt at participating. So, this is what I wonder, you feel comfortable speaking English to each other?

12 Luigi: We are not in the same situation here. Because this is your country, this is not mine. So if you, generally speaking, if a Swedish person doesn't feel comfortable speaking in English with another Swedish person and so on and so forth, well, you need to consider that they are actually in their country, and in a way this is also something that we might want to consider. In the case of me, Rafael and me, it is different, because we are actually guests basically. And it is not precisely that Italian is the language here, and I am graciously shifting to English to include you. It is actually probably a common ground which we are looking for.

Luigi (line 12) holds that Swedish speakers cannot be expected to follow the same principles for discursive inclusion as international staff members, ultimately because Sweden is their country. In fact, he seems to consider himself and his Italian fellows as temporarily dwelling in Swedish university life. This self-understanding guides his sense of value of Italian in the workplace and justifies his linguistic subordination to the market conditions at work. For reasons of space, he holds, their situation is not comparable to that of 'Swedish persons' - a labeled social collective they do not envision themselves to be part of. In Luigi's office, however, other linguistic market conditions apply, ultimately because the office is perceived as a more private physical space, where the historically contingent market conditions that are actualized in common spaces do not apply equally. In their offices, Italian seemingly holds a heightened market value, and it is here 'reinforced by calls to order from the group, that is to say, from the aggregate of the individuals endowed with the same dispositions, to whom each is linked by his dispositions and interests' (Bourdieu 1977:15).

\section{O N C L U D IN G REMAR K S}

Merton (1942/1973:271) once remarked that 'the institution of science is part of a larger social structure with which it is not always integrated'. Language, to be sure, is part of that structure, which is why the question of legitimate language use in academe matters. In this light, it is evident that academe, as a subspace of society, can be approached from the viewpoint of language, whereas language, conversely, 'can be approached from the viewpoint of society, as an extraordinarily sensitive index of social relationships, processes and development' (Blommaert 2015:12). Using the inroads provided by language, as this article proposes, university life is best conceived as positioned in a space that is, at once, national and international. Beyond the Anglophone world, as the Swedish case illustrates, this 
'all-at-onceness' has implications for linguistic practice, ultimately because the national space seems bound up with national languages, whereas the international space is bound up with English. As this article has sought to demonstrate empirically, a feature of this global condition is that it engenders a particular type of oscillating language use: a spatial logic of linguistic practice.

In internationalizing academe, to be sure, there are linguistic market conditions operating in favor of English, which, reflecting and reinforcing the present-day sociolinguistic order of global science, gives English an indispensable position as the language of publishing practices and beyond. Global influxes of staff also make the lingua franca, English, a requisite collective asset in the workplace. Yet, the accounts presented in this article maintain that Swedish-speaking scholars hold Swedish to be the natural, that is, the legitimate, language to use among themselves. Thus, another coterminous spatial logic — a set of historically contingent linguistic market conditions - operates in favor of Swedish. I argue that English use among Swedish-speaking dwellers is socially constrained by the unease of being out of place (Bourdieu 2000), inculcated in their socially endowed dispositions to linguistic practice. For them, upholding the principle of speaking Swedish between themselves is to conform to market conditions imbued in specific situations, and to produce language in accordance with a tacit yet authoritative idea of sociolinguistic acceptability imbued in the specific situations where only Swedish speakers interact.

Sociologically, this logic differs from accounts of language choice that treat physical location, domain, space, or place as a decisive factor in and of itself. Following De Certeau, Higgins argues that 'space is a practiced place, and just because places have been established, their material aspects do not determine people's behavior' (Higgins 2017:103). This article generally concurs with this view. Yet, the Bourdieusian gaze adopted here is attuned to treating physical space as a template that provides certain material conditions for social practices, including linguistic practices, chiefly based on the presences and absences of particular social agents and the linguistic habitus they enact in practice. Hence, the emphasis on habitus is what makes Bourdieu's account distinct, as a lynchpin for fusing conceptually the embodiment of social and physical space, and so grasping the banality of linguistic practice (cf. Cresswell 2002:381). One implication of this argument is that physical space is, often, a misrecognition of habitus and the social space it carries with it into linguistic practices. To be sure, it is in physical locations that embodied action takes place; nonetheless, in that physical locations are already social, they affect language practices primarily by virtue of the practices associated with particular physical spaces, and, most importantly, the agents taking part in such practices. Their bodily presence, in this view, becomes a part of the physical space, which in turn alters linguistic market conditions. This approach to embodied experience as construing spatiality among socialized language users provides a refined understanding of processes of sociolinguistic perception, 'which enables one's sense of physical space to bleed over into one's sense of the social, and 
therefore to one's sense of place in social space' (Fogle 2011:86). I submit that speakers are socialized into this logic: dwelling endows speakers with embodied knowledges about linguistic naturality and acceptability, and instills in them 'a sense of the equivalences between physical space and social space' (Bourdieu 1990:71).

In this way, social space - as instantiated in immediate physical space-is brought to bear on spatially locked-down agents. The computer scientist, psychologist, mathematician, and historians whose linguistic practices were explored in this article all amplify the point that socialized agents (i) have acquired an incorporated sense of the values ascribed to linguistic assets in various markets, (ii) understand the value of their own linguistic assets, and (iii) make use of this practical knowledge in the production of linguistic practice. These are the core constituents of their linguistic sense of placement that significantly affect language use. Nevertheless, prolonged dwelling in academe and its social subuniverses prompts people to speak about their mundane linguistic practices as being spatially inclined: physical space becomes a way of apprehending particular patterns in the spatial distribution of linguistic assets. As a result, physical space is readily used to grasp rationally a certain linguistic behavior. As an effect, social agents not only speak spatially-in line with their linguistic sense of placement — but speak about their speaking in spatial terms.

Repeatedly throughout the extracts, we see rationalizing attempts to present practices as logical. Indeed, part of the habitus is the capacity to render everyday behavior reasonable in accounting practices; in Hanks' words: 'Assumed, habituated, and schematized in the habitus, systems of difference appear self-evident' (2005:77). Often, people are unaware or oblivious of the fact that they exercise or suffer from symbolic violence and reap symbolic profits as their linguistic habitus encounters a certain space - physical and, at once, social. For those who pass as Swedishspeakers, using Swedish with other Swedish-speakers who share a similar sense is conceived as 'natural', that is, aligned to a shared notion of acceptability imbued in these situations. Non-Swedish-speakers relate to this logic, too. As skillful speakers, they too have a practical sense of the game of using language in ways that align with perceived market values, and their linguistic habitus is the incarnation of that sense - 'the product of a practical sense, of a particular social game' (Lamaison \& Bourdieu 1986:112). The British mathematician's first language is the same language, English, through which internationalizing academe increasingly operates. Dwelling in Swedish academe, however, he is confronted with market conditions that ascribe ample value also to Swedish, an order to which he is highly sensitized. For the Italian historians, it seems reasonable, 'natural', to subordinate themselves to the same market logic of sanctions and censorships that ascribes legitimacy to two languages - Swedish and English - in common spaces. Behind the closed doors of their offices, Italian linguistic assets are valorized and subsequently used. By eschewing Italian in common spaces, their linguistic practices neatly illustrate that the spatial logic of linguistic practice presented here is not rule-obeying but 
strategy-inclined, aligned with the sociolinguistic order infusing the workplace. Their practices are produced by their sense of the game of how to dwell in Swedish academe linguistically.

By way of concluding, let us return to Pasteur's old dictum that science, unlike scientists, has no homeland. This view-deeply engrained in contemporary SP worldwide - may be fruitfully problematized through the study of language in the realm of science. It might well be that knowledge, as the saying goes, 'knows no boundaries'. Yet, given that scientific knowledge is produced by nationally positioned scientists, the idea of completely displacing science from its producers and contexts of origin seems naïve at best. Pasteur knew this. In 1888, he proclaimed that 'If science does not have a homeland, then the man of science must have one, and to it he owes the influence his work may have in the world' (quote from Gingras 2002:31, my translation). Hence, Pasteur cherished intellectually internationalism and national attachment in equal measures. Notably, he produced globally valuable knowledge through the medium of French and would probably not have endorsed the idea that the use of multiple languages strains scientific universalism. Subsequently, internationalization policies that postulate academe to be inherently international, and thus normatively English-dominated, not only a lack a sound basis but downplay academe as a site of struggle, where matters of interest and power unfold.

\section{N O T E S}

*This work was produced within the knowledge-platform Making Universities Matter, funded by Sweden's Innovation Agency (2015-04473; 2019-03679). I thank the journal's editors, two reviewers, and the following colleagues for comments that greatly improved the manuscript: David Karlander, Linnea Hanell, Luke Holmes, Lamont Antieau, Fredrik Bertilsson, Marco Santello, and Suresh Canagarajah.

${ }^{1}$ For example, this trope was recently utilized by the European Commissioner for Research, Science \& Innovation, Carlos Moedas, Brazil November 17, 2015.

${ }^{2}$ This extract appeared in Salö (2015) and is here reused with permission from Wiley.

\section{R E F E R E N C E S}

Blommaert, Jan (2015). Pierre Bourdieu: Perspectives on language in society. In Jef Verschueren \& Jan-Ola Östman (eds.), Handbook of pragmatics 2015 installment, 1-16. Amsterdam: John Benjamins.

— James Collins; \& Stef Slembrouck (2005). Spaces of multilingualism. Language \& Communication 25:197-216.

Bourdieu, Pierre (1970). The Berber house or the world reversed. Social Science Information 9(2):151-70.

(1977). Outline of a theory of practice. Cambridge: Cambridge University Press.

(1990). The logic of practice. Stanford, CA: Stanford University Press.

(1991). Language and symbolic power. Cambridge: Polity.

(1993a). Site effects. In Pierre Bourdieu et al., The weight of the world: Social suffering in contemporary society, 123-29. Stanford, CA: Stanford University Press.

(1993b). Sociology in question. London: SAGE. 


\section{LINUS SALÖ}

(1996). Physical space, social space and habitus. Report 10:1996. Oslo: University of Oslo, Department of Sociology.

- (2000). Pascalian meditations. Cambridge: Polity.

(2017). Manet: A symbolic revolution. Cambridge: Polity.

; Jean-Claude Passeron; \& Monique De Saint Martin (1965/1994). Academic discourse: Linguistic misunderstanding and professional power. Cambridge: Polity.

Canagarajah, Suresh (2013). Translingual practice: Global Englishes and cosmopolitan relations. London: Routledge.

Crawford, Elisabeth; Terry Shinn; \& Sverker Sörlin (eds.) (1993). Denationalizing science: The contexts of international scientific practice. Dordrecht: Kluwer.

Cresswell, Tim (2002). Bourdieu's geographies: In memorium. Environment and Planning D: Society and Space 20:379-82.

Curtis, Elizabeth (2015). The place of time in children's being. In Abigail Hackett, Lisa Procter, \& Julie Seymour (eds.), Children's spatialities: Embodiment, emotion and agency, 39-53. London: Palgrave.

Dubois, Michel; Yves Gingras; \& Claude Rosental (2016). Practices and rhetoric of the internationalization of science. Revue Française de Sociologie 3(57):407-15.

Ehn, Billy, \& Orvar Löfgren (2010). The secret art of doing nothing. Berkeley: University of California Press.

Fogle, Nikolaus (2011). The spatial logic of social struggle: A Bourdieuian topology. New York: Rowman \& Littlefield.

Gingras, Yves (2002). Les forms spécifiques de l'internationalité du champ scientifique. Acte de la Recherche en Sciences Sociales 2(141):31-45.

Goodwin, Charles (1994). Professional vision. American Anthropologist 96(3):606-33.

Hanks, William F. (1996). Language and communicative practices. Boulder, CO: Westview.

(2005). Pierre Bourdieu and the practices of language. Annual Review of Anthropology 34:67-83.

Hazel, Spencer, \& Janus Mortensen (2013). Kitchen talk: Exploring linguistic practices in liminal institutional interactions in a multilingual university setting. In Hartmut Haberland, Dorte Lønsmann, \& Bent Preisler (eds.), Language alternation, Language choice and language encounter in international tertiary education, 3-30. Dordrecht: Springer.

Heller, Monica (2011). Paths to post-nationalism. A critical ethnography of language and identity. Oxford: Oxford University Press.

Higgins, Christina (2017). Space, place, and language. In Suresh Canagarajah (ed.), The Routledge handbook of migration and language, 102-16. New York: Routledge.

Hollqvist, Håkan (1984). The use of English in three large Swedish companies. Uppsala: Uppsala University.

Ingold, Tim (2000). The perception of the environment: Essays on livelihood, dwelling and skill. New York: Routledge.

Jaworski, Adam, \& Crispin Thurlow (2010). Semiotic landscapes. Language, image, space. New York: Bloomsbury.

Koller, Veronika (2018). Language awareness and language workers. Language Awareness 27(1-2):4-20.

Lamaison, Pierre, \& Pierre Bourdieu (1986). From rules to strategies: An interview with Pierre Bourdieu. Cultural Anthropology 1(1):110-20.

Markus, Thomas A., \& Deborah Cameron (2002). The words between the spaces: Buildings and language. New York: Routledge.

Massey, Doreen (2005). For space. London: SAGE.

Melander, Björn (2001). Swedish, English and the European Union. In Sally Boyd \& Leena Huss (eds.), Managing multilingualism in a European nation-state, 13-31. Clevedon: Multilingual Matters.

Merton, Robert (1973). The normative structure of science. In Robert Merton (ed.), The sociology of science: Theoretical and empirical investigations, 267-78. Chicago: University of Chicago Press. 


\section{THE SPATIAL LOGIC OF LINGUISTIC PRACTICE}

Ministry of Culture (2008). Värna språken - förslag till språklag. Report SOU 2008:26. Online: https:// www.regeringen.se/49bb98/contentassets/80e573241bbc4ce595510810065fd59e/varna-sprakenforslag-till-spraklag-sou-200826.

Ministry of Education and Research (2018). En strategisk agenda för internationalisering. Report SOU 2018:3. Online: https://www.regeringen.se/490aa7/contentassets/2522e5c3f8424df4aec78d2e 48507e4f/en-strategisk-agenda-for-internationalisering.pdf.

Negretti, Rafaella, \& Miguel Garcia-Yeste (2015). 'Lunch keeps people apart': The role of English for social interaction in a multilingual academic workplace. Multilingua 34(1):93-118.

Pennycook, Alastair, \& Emi Otsuji (2015). Metrolingualism: Language in the city. New York: Routledge.

Salö, Linus (2015). The linguistic sense of placement: Habitus and the entextualization of translingual practices in Swedish academia. Journal of Sociolinguistics 19(4):511-34.

(2016). Languages and linguistic exchanges in Swedish academia: Practices, processes, and globalizing markets. Stockholm: Centre for Research on Bilingualism.

(2018). Thinking about language with Bourdieu: Pointers for social theory in the language sciences. Sociolinguistic Studies 12(3/4):523-43.

, \& Linnea Hanell (2014). Performance of unprecedented genres: Interdiscursivity in the writing practices of a Swedish researcher. Language \& Communication 37:12-28.

Söderlundh, Hedda (2012). Global policies and local norms: Sociolinguistic awareness and language choice at an international university. International Journal of the Sociology of Language 2012 (216):87-109.

Thompson, John B. (1984). Studies in the theory of ideology. Berkeley: University of California Press. (1991). Editor's introduction. In Pierre Bourdieu, Language and symbolic power, 1-31. Cambridge: Polity.

(Received 19 November 2019; revision received 29 November 2019; accepted 08 March 2020; final revision received 08 April 2020)

Address for correspondence:

Linus Salö

Stockholm University

Centre for Research on Bilingualism

SE-106 91 Stockholm, Sweden linus.salo@biling.su.se 